\title{
Cyclic acetals as coinitiators in CQ-induced photopolymerizations
}

\author{
Kemin Wang, Guiping Ma, Xiaohua Qin, Ming Xiao and Jun Nie
}

A series of cyclic acetals were investigated with regard to their ability to function as coinitiators in free-radical photopolymerization induced by camphorquinone (CQ). Among these cyclic acetals, the reactivity of 2-hexyl-1,3-benzodioxole (HBDO) was the highest, according to the quantum yield of CQ. However, the most efficient coinitiator was I,3-benzodioxolane, which has a reactivity significantly exceeding that of HBDO. The polymerization efficiency of the coinitiators did not correlate with the efficiency of the photoinduced formation of the initiating radicals. The reasons for this lack of correlation were discussed in terms of how the reactivity of the radicals formed affected the various stages of polymerization. Further studies with a cleavage-type photoinitiator in the presence of cyclic acetals provided supporting evidence for the role of the chaintransfer reaction in the polymerization of the $\mathrm{CQ} /$ cyclic acetal systems.

Polymer Journal (2010) 42, 450-455; doi:10.1038/pj.2010.29; published online 12 May 2010

Keywords: cyclic acetal; photopolymerization; photoreduction

\section{INTRODUCTION}

Photoinitiated free-radical polymerization is of great commercial importance. ${ }^{1,2}$ Many techniques, including curing of coatings on various materials and the manufacture of adhesives, printing inks and photoresists, are based on photoinitiated free-radical polymerization of vinyl monomer. Varieties of free radical initiators are now clearly recognized as powerful polymerization-initiating agents. Photoinitiated free-radical polymerizations are usually carried out in the presence of photoinitiators of the 'cleavage' type (type I) or of the hydrogen abstraction type (type II). ${ }^{3,4}$ Type II photoinitiators are a class of photoinitiators based on compounds, the triplet excited states of which readily react with hydrogen donors, thereby producing initiating free radicals. ${ }^{5,6}$

Camphorquinone (CQ), a type II photoinitiator, has been used extensively in restorative dentistry as the introduction of visible-lightactivated resin composites. To produce radicals efficiently, CQ is commonly used with amine coinitiators. ${ }^{7-9}$ However, the use of amine coinitiators often leads to yellowing. In addition, amines are both toxic and mutagenic. ${ }^{10-14}$ Thus, it is important to investigate new, efficient coinitiators for CQ.

Because the active hydrogen between the two alcohoxy groups in cyclic acetals can be abstracted to form free radicals, the photochemical rearrangement mechanism of 1,3-dioxolane compounds to yield esters is possible. ${ }^{15,16}$ The monoester free radical generated by the photoirradiation of cyclic acetal compounds can initiate the polymerization of vinyl compounds. ${ }^{17,18}$ Photosensitized hydrogen abstraction from 2-alkyl-1,3-dioxolanes by triplet benzophenone yields the corre- sponding 1,3-dioxolan-2-yl free radicals, and these free radicals are trapped by $\alpha, \beta$-unsaturated ketones yielding monoprotected 1,4diketones. ${ }^{19}$ Shi et al. ${ }^{20}$ reported that cyclic acetals were used as hydrogen donors for bimolecular photoinitiating systems, and 1,3benzodioxole (BDO) was used as a coinitiator, replacing the conventional amine for dental composites. ${ }^{20,21}$

In this study, cyclic acetals were used as hydrogen donors for CQ photoinitiating systems. The primary photochemical reaction between CQ and a series of cyclic acetal derivatives, their activity in photoreduction of CQ and their efficiency as coinitiators in CQ-induced polymerization were studied. To investigate the effect of the reactivity of a series of cyclic acetal derivatives as coinitiators, ultraviolet-visible (UV-vis) spectra of CQ and of different cyclic acetal systems were collected. The synergistic effect of cyclic acetals and CQ was investigated using real-time near-Fourier transform infrared spectra.

\section{EXPERIMENTAL PROCEDURE}

Materials

1,3-Benzodioxolane (98\%, Sigma-Aldrich Inc., St Louis, MO, USA), 2,2-bis[4(2-hydroxyl-3-methacryl-oxypropoxy)phenyl]-propane (bis-GMA, SigmaAldrich Inc.) and triethylene glycol dimethacrylate (TEGDMA, donated by Sartomer Company, Warrington, PA, USA) were used without further purification. CQ and 2,2-dimethoxy phenylacetophenone (Sigma-Aldrich) were used as photoinitiators. Cyclohexane was dried and purified according to standard laboratory methods. All other reagents, solvents and materials were obtained from Sinopharm Group Chemical Reagent Beijing Co. Ltd. (Beijing, China), and used as received, unless otherwise specified. 
1,2-isopropylidendioxybenzene (DMBDO), spiro [1,3-benzodioxole-2,1'cyclohexane] (CHBDO), 2-proply-1,3-benzodioxole (PBDO) and 2-hexyl-1, 3-benzodioxole (HBDO) were synthesized from catechol with the corresponding aldehyde or ketone using p-toluenesulfonic acid as a catalyzer as previously described ${ }^{22-24}$

DMBDO Yields: $70 \% .{ }^{1} \mathrm{H}$ NMR $\left(\mathrm{CDCl}_{3}\right) \delta=1.67(6 \mathrm{H})$ and $6.72-6.78(4 \mathrm{H})$. CHBDO Yields: $28 \% .{ }^{1} \mathrm{H}$ NMR $\left(\mathrm{CDCl}_{3}\right) \delta=1.49-1.91(10 \mathrm{H}$, cyclohexylidene $\mathrm{CH})$ and $6.74-6.75(4 \mathrm{H}$, aromatic $\mathrm{H})$.

PBDO Yields: $23 \%$. ${ }^{1} \mathrm{H}$ NMR $\left(\mathrm{CDCl}_{3}\right) \quad \delta=1.02-1.94(7 \mathrm{H}), 6.11(1 \mathrm{H})$, $6.76-6.79(4 \mathrm{H})$

HBDO Yields: $45 \% .{ }^{1} \mathrm{H}$ NMR $\left(\mathrm{CDCl}_{3}\right) \quad \delta=0.87-1.97(13 \mathrm{H}), 6.09(1 \mathrm{H})$, $6.75-6.79(4 \mathrm{H})$.

(The chemical structures of photoinitiators and coinitiators are shown in Figure 1.)

\section{Characterization}

${ }^{1} \mathrm{H}$ NMR spectra were recorded on a BrukerAV600 (Bruker Analytik GmbH, Rheinstetten, Germany) unity spectrometer operated at $600 \mathrm{MHz}$, with $\mathrm{CDCl}_{3}$ as a solvent. Fourier transform infrared spectra were recorded on a Nicolet 5700 instrument (Thermo Electron, Waltham, MA, USA). UV-vis absorption spectra were recorded in an absolute ethanol or cyclohexane solution on a Hitachi U-3010 UV-vis spectrophotometer (Hitachi High-Technologies, Tokyo, Japan). A cell path length of $1 \mathrm{~cm}$ was used.

The visible light source was Spectrum 800 Curing Light (Dentsply, Milford, DE, USA)

The visible light radiometer was a UV-A radiometer in the range of 4001000 nm (Photoelectric Instrument Factory, Beijing Normal University, China).

\section{Photoreduction}

Photoreduction of CQ and amine was studied using UV absorption spectroscopy. Cyclic acetals and CQ were dissolved in cyclohexane. The concentrations of CQ and cyclic acetals were $1.5 \times 10^{-3}$ and $1.0 \times 10^{-3} \mathrm{moll}^{-1}$, respectively. All measured solutions were deoxygenated by bubbling nitrogen into the solution for $30 \mathrm{~min}$. The relative rate of photoreduction was determined by measuring the decrease in the peak absorbance of CQ at $468 \mathrm{~nm}$ with irradiation time. The light intensity on the cell surface was $20 \mathrm{~mW} \mathrm{~cm}^{-2}$. The rate of CQ disappearance $(\mathrm{Rd})$ was calculated according to the following equation:

$$
\mathrm{Rd}=-\mathrm{d}[\mathrm{CQ}] / \mathrm{d} t=-\left([\mathrm{CQ}] / \mathrm{Ab}_{0}\right) \times(\mathrm{d}[\mathrm{Ab}] / \mathrm{d} t)
$$

where $A b_{0}$ and $\mathrm{Ab}$ are the absorbance of CQ at $468 \mathrm{~nm}$ before and after exposure to visible light.

The quantum yield of the CQ photoreduction ( $\Phi C Q)$ was calculated from the following equation: ${ }^{25}$

$$
\begin{aligned}
\text { ФCQ } & =(\mathrm{d}[\mathrm{CQ}] / \mathrm{d} t) \times I_{\mathrm{a}} \\
& =(\mathrm{d}[\mathrm{CQ}] / \mathrm{d} t) \times I_{0}\left(1-10^{\mathrm{Ab} 468}\right) \varepsilon_{468} \times[\mathrm{CQ}] / \mathrm{Ab}_{468}
\end{aligned}
$$

where $I_{0}$ is the incident light intensity at $468 \mathrm{~nm}\left(\mu \mathrm{Wcm}^{-2}\right)$ on the front surface of the cell, $\mathrm{Ab}_{468}$ is the total absorbance of CQ and 8468 is 40 in cyclohexane. ${ }^{26}$

\section{Polymerization kinetics}

The rate of polymerization $\left(\mathrm{R}_{\mathrm{p}}\right)$ profiles and double bond conversions (DC) were determined by real-time IR spectroscopy. The initiating system consisted of the initiator (CQ), the coinitiator (cyclic acetals) and the photopolymerable monomer (TEGDMA). The mixtures of TEGDMA, the initiator and the coinitiator were placed in a mold made from a glass slide and spacers with a diameter of $15 \pm 1 \mathrm{~mm}$ and thickness of $1.2 \pm 0.1 \mathrm{~mm}$. The samples were placed in a Fourier transform infrared spectrometer and were simultaneously exposed to a visible/UV light source and an IR-analyzing light beam. The light intensity on the sample was $100 \mathrm{~mW} \mathrm{~cm}^{-2}$. The spectrometer was operated in the absorbance mode, and the absorbance change of the $=\mathrm{C}-\mathrm{H}$ peak area from 6101 to $6219 \mathrm{~cm}^{-1}$ in the near IR range was correlated to the extent of polymerization. The degree of conversion, DC, can be expressed by the following relation:

$$
\mathrm{DC} \%=\left(A_{0}-A_{t}\right) \times 100 / A_{0}
$$

where $\mathrm{A}_{0}$ is the initial peak area before irradiation and $\mathrm{A}_{t}$ is the peak area of the double bonds at $t$ time. For each sample, real-time IR spectroscopy runs were repeated three times.

\section{RESULTS AND DISCUSSION}

CHBDO, DMBDO, HBDO and PBDO (Figure 1) were synthesized using a previously described method. ${ }^{22-24}$ The structures of the cyclic acetals were confirmed by spectrum analysis (see Experimental procedure section).

\section{Photoreduction}

CQ absorbs visible light in the region of $400-500 \mathrm{~nm}$ (explaining its yellow color) with a maximum at $470 \mathrm{~nm}$ because of the $n-\pi^{*}$ transition of the $\alpha$-dicarbonyl chromophore. Photoreduction studies were conducted with visible light irradiation in the region of 400$550 \mathrm{~nm}$. During the visible light irradiation of CQ/CHBDO and CQ/ $\mathrm{BDO}$ in cyclohexane, the absorption band of CQ in the range of 400$550 \mathrm{~nm}$ decreased, as shown in Figure 2. Spectra of CQ/DMBDO, CQ/ HBDO and CQ/PBDO at the same condition showed a similar trend. The decrease in the maximum absorbance of CQ at $468 \mathrm{~nm}$ in the presence of cyclic acetals and without cyclic acetals is presented in Figure 3. The absorbing peak of CQ without cyclic acetals was nearly constant during the irradiation process. The addition of any kind of cyclic acetals decreased the maximum absorbance peak of CQ, and this decrease was proportional to the irradiation time.

The rate of CQ disappearance and the quantum yield of CQ photoreduction for the five systems were dependent on the cyclic acetal structure, as presented in Table 1 . The quantum yields of CQ decreased in the following order: $\mathrm{HBDO}>\mathrm{DMBDO}>\mathrm{PBDO}>$ $\mathrm{CHBDO}>\mathrm{BDO}$

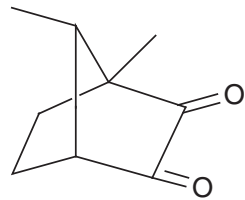

$C Q$<smiles>c1ccc2c(c1)OC1(CCCCC1)O2</smiles>

CHBDO<smiles>c1ccc2c(c1)OCO2</smiles>

$\mathrm{BDO}$<smiles>CCCCCCC1Oc2ccccc2O1</smiles>

HBDO<smiles>CCCC1Oc2ccccc2O1</smiles>

PBDO<smiles>CC1(C)Oc2ccccc2O1</smiles>

DMBDO

Figure 1 Chemical structures of $C Q$ photoinitiators and cyclic acetal coinitiators. 

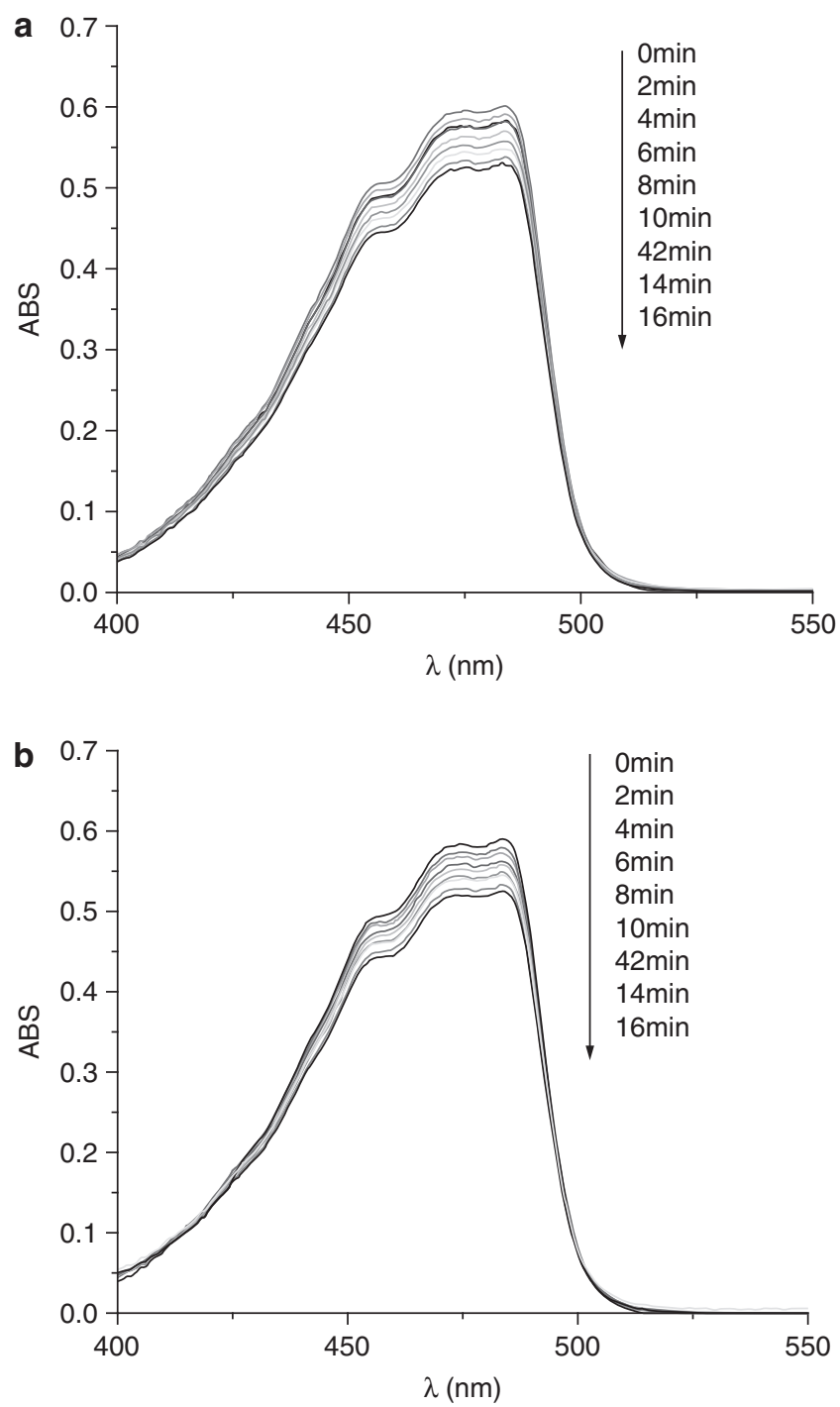

Figure 2 Change in the UV-vis absorption spectra of $C Q$ in the presence of CHBDO (a) and BDO (b) in cyclohexane during irradiation at $468 \mathrm{~nm}$ after $30 \mathrm{~min}$ of nitrogen bubbling $\left((\mathrm{CQ})=1.5 \times 10^{-3} \mathrm{moll}^{-1},(\mathrm{CHBDO})=(\mathrm{BDO})=1.0 \times\right.$ $10^{-3} \mathrm{~mol} \mathrm{I}^{-1}, l=20 \mathrm{~mW} \mathrm{~cm}^{-2}$ ).

This trend indicated that the chain length and the number of substituent groups affected the charge transfer and proton abstraction between ${ }^{3} \mathrm{CQ}^{*}$ and the cyclic acetals.

\section{Photopolymerizations}

Real-time near-Fourier transform infrared is a convenient method to monitor the extent of polymerization in thick $(1 \mathrm{~mm})$ photocured samples. ${ }^{27,28}$ On irradiation, the extent of polymerization as a function of time was accurately reflected by measuring the decrease of the $=$ $\mathrm{C}-\mathrm{H}$ absorbance peak area. The rate of polymerization $\left(\mathrm{R}_{\mathrm{p}}\right)$ could be calculated by the time derivative of the DC curve. ${ }^{29}$ The induction time $\left(T_{\mathrm{i}}\right)$ and the maximum rate of polymerization $\left(\mathrm{R}_{\mathrm{p}}^{\max }\right)$ were obtained from the Rp curves as a function of irradiation time.

The kinetic curves presented in Figure 4 reflect the activity of the investigated cyclic acetals that functioned as coinitiators for CQ in TEGDMA photopolymerizations. The data for $\left(\mathrm{R}_{\mathrm{p}}^{\max }\right), T_{\mathrm{i}}$ and the final conversion of polymerization $\left(\mathrm{DC}_{\mathrm{f}}\right)$ are shown in Table 2 .

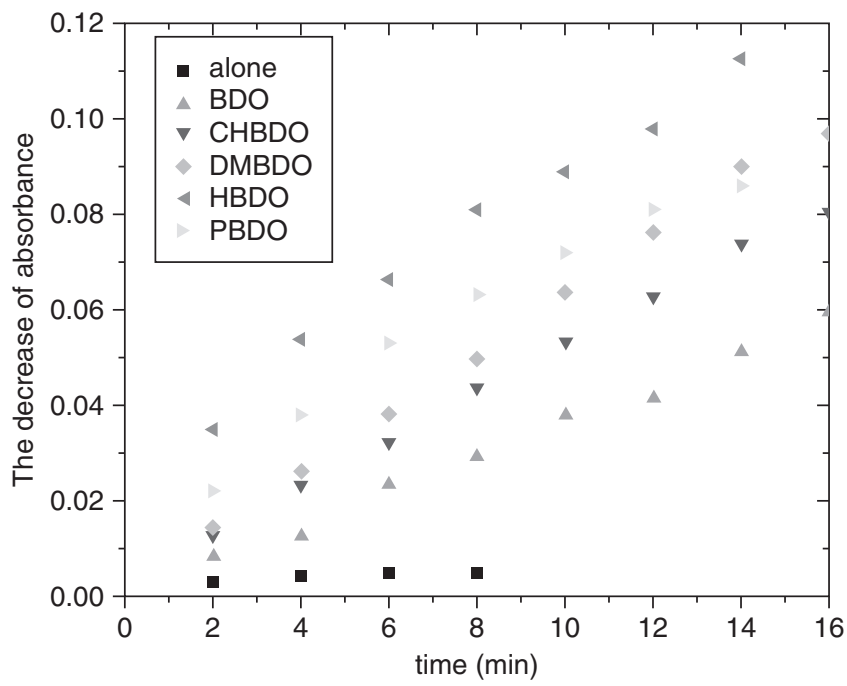

Figure 3 Kinetics of the disappearance of the $C Q$ absorption band at $468 \mathrm{~nm}$ in the presence of different cyclic acetals in cyclohexane during irradiation $\left((\mathrm{CQ})=1.5 \times 10^{-3} \mathrm{moll}^{-1}, \quad(\right.$ cyclic acetals $)=1.0 \times 10^{-3} \mathrm{moll}^{-1}$, $I=20 \mathrm{~mW} \mathrm{~cm}^{-2}$ ) after $30 \mathrm{~min}$ of nitrogen bubbling.

The results presented in Figure 4 and Table 2 show that all coinitiators increased the final DC, and the ability of cyclic acetals to increase the $\left(\mathrm{R}_{\mathrm{p}}^{\max }\right)$ decreased in the following order: $\mathrm{BDO}>$ $\mathrm{DMBDO}>\mathrm{PBDO}>\mathrm{CHBDO} \geqslant$ no coinitiator $>\mathrm{HBDO}$.

Thus, the largest increase in $\left(\mathrm{R}_{\mathrm{p}}^{\max }\right)$ was observed in the presence of BDO but not of HBDO, which had the highest quantum yield of CQ photoreduction.

The lack of a direct correlation between the activities of cyclic acetals in CQ photoreduction and the acceleration of polymerization rate may be traced to two factors: the initiation rate and the chaintransfer reaction (see Scheme 1).

The initiation rate was not only determined by the efficiency of radical formation given by $\Phi C Q$ (Path b1, Scheme 1) but also depended on the contributions from paths a1 and a2, as well as on the reactivity of the CC radicals formed (path b2, Scheme 1) in the initiation process. The second factor spoiling the correlation was the chain-transfer reaction, in which active coinitiators that possessed labile hydrogen atoms may be involved. ${ }^{30}$

The relative efficiency of the CQ/cyclic acetal system changed when the monomer (or mixtures of monomers) had high viscosity. An example was the Bis-GMA (2-2-bis[4-(2-hydroxy-3-methacryloxyprop-1-oxy)phenyl]propane)/TEGDMA (70/30 wt \%) mixture, which is widely used in dental applications. The reactions between CQ and coinitiators could be diffusion controlled from the very beginning of the polymerization process. Because the monomer mixture had high viscosity, chain-transfer reactions had low probability. It appeared that the contributions of paths a1 and a2 to the initiation process were about the same in each polymerizing system. As a consequence, the main factor controlling the polymerization rate was the reactivity of the primary free radicals.

The kinetic curves of the Bis-GMA/TEGDMA(70/30 wt \%) initiated by the $\mathrm{CQ} /$ coinitiator system, shown in Figure 5, demonstrated that the most efficient coinitiators were BDO, HBDO and PBDO. Even the cyclic acetal HBDO, which suppressed TEGDMA polymerization, was an efficient coinitiator for CQ in the polymerization of the Bis-GMA/ TEGDMA (70/30 wt \%) mixture. The ability of BDO, HBDO and 
Table 1 The rate of $C Q$ disappearing and the quantum yield of $C Q$ photoreduction for the five systems in cyclohexane

\begin{tabular}{lccccc}
\hline & $H B D O$ & $D M B D O$ & $P B D O$ & $C H B D O$ & $B D O$ \\
\hline $\mathrm{Rd} \times 10^{7}\left(\mathrm{~mol} \mathrm{I}^{-1} \mathrm{~S}^{-1}\right)$ & 2.93 & 2.67 & 2.51 & 2.14 & 1.62 \\
$\Phi_{\mathrm{CQ} \times 10^{3}}$ & 1.21 & 1.03 & 0.99 & 0.84 & 0.61 \\
\hline
\end{tabular}

Abbreviations: BDO, I,3-benzodioxolane; CHBDO, [1,3-benzodioxole-2,I'- cyclohexane]; CQ, camphorquinone; DMBDO, 1,2-isopropylidendioxybenzene; HBDO, 2-hexyl-1, 3-benzodioxole; PBDO, 2-proply-1,3-benzodioxole.
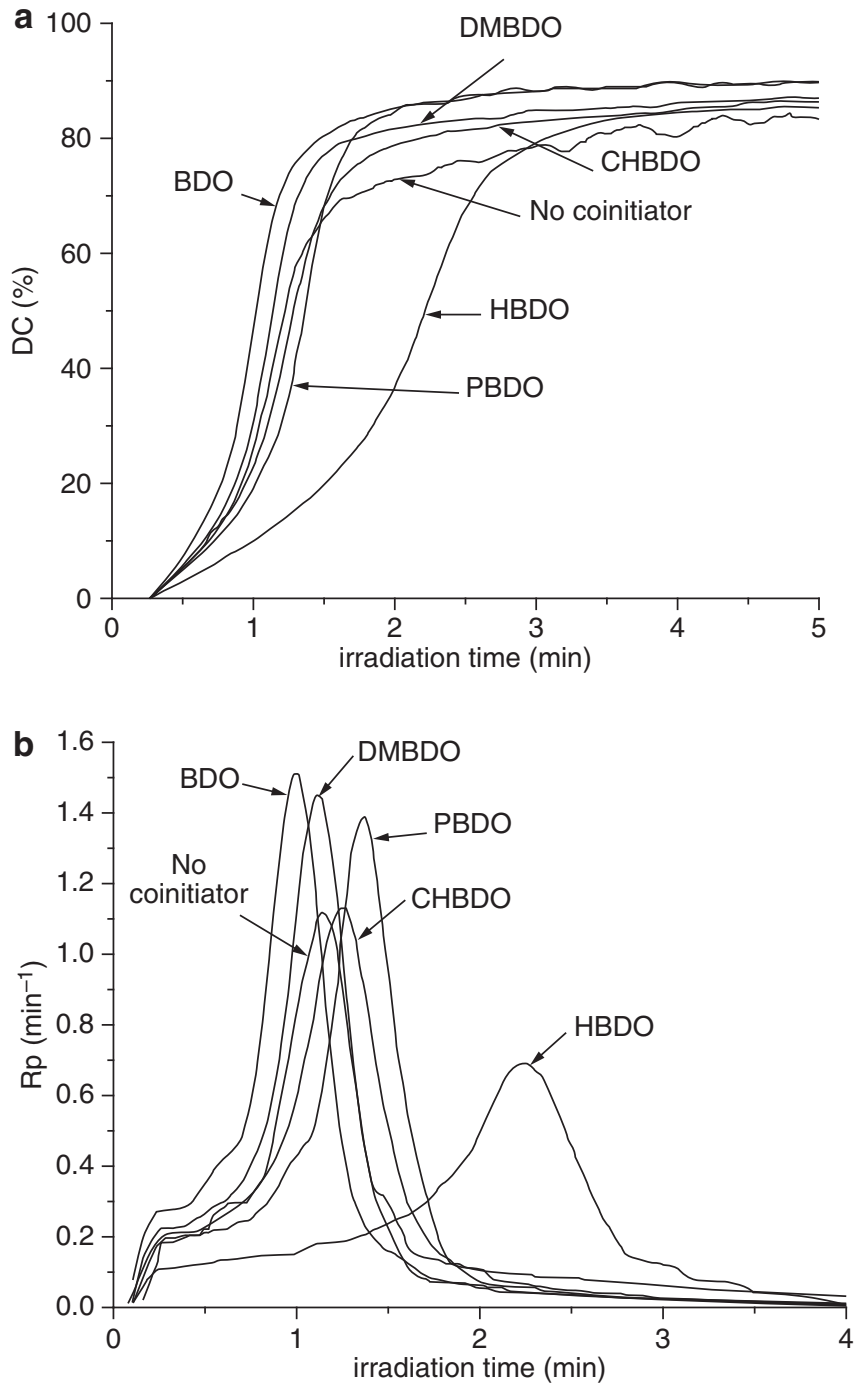

Figure 4 The $\mathrm{DC}$ (a) and $R_{\mathrm{p}}$ (b) as a function of irradiation time for TEGDMA bulk photopolymerizations $(C Q)=($ cyclic acetal $)=1 \times 10^{-4} \mathrm{~mol} \mathrm{~g}^{-1}$, $I=100 \mathrm{~mW} \mathrm{~cm}^{-2}$

PBDO to accelerate polymerization was higher than that of DMBDO and $\mathrm{CHBDO}$. These findings indicated that the reactivity of the primary free radicals of $\mathrm{BDO}, \mathrm{HBDO}$ and $\mathrm{PBDO}$ was higher than that of DMBDO and CHBDO.

The effect of the chain-transfer reaction can be isolated from that of initiation by the addition of cyclic acetals to a polymerizing system initiated by a 'cleavage-type' photoinitiator. The results for TEGDMA polymerization initiated by 2,2-dimethoxy phenylacetophenone in the presence of various cyclic acetals are given in Figure 6. Because of the
Table 2 Photopolymerization of TEGDMA initiated by CQ $\left(1 \times 10^{-4} \mathrm{~mol} \mathrm{~g}^{-1}\right)$ without/with cyclic acetal $\left(1 \times 10^{-4} \mathrm{~mol} \mathrm{~g}^{-1}\right)$ with an intensity of $100 \mathrm{~mW} \mathrm{~cm}^{-2}$

\begin{tabular}{lccc}
\hline Cyclic acetals & $T_{i}(\min )$ & $R_{\mathrm{p}}^{\max }\left(\mathrm{min}^{-1}\right)$ & $D C_{f}(\%)$ \\
\hline No coinitiator & 1.14 & 1.12 & 83.42 \\
BDO & 0.98 & 1.51 & 89.91 \\
CHBDO & 1.24 & 1.13 & 85.42 \\
DMBDO & 1.11 & 1.45 & 86.93 \\
HBDO & 2.25 & 0.69 & 86.49 \\
PBDO & 1.37 & 1.39 & 89.65
\end{tabular}

Abbreviations: BDO, I,3-benzodioxolane; CHBDO, [1,3-benzodioxole-2,I'-cyclohexane]; CQ, camphorquinone; DMBDO, 1,2-isopropylidendioxybenzene; HBDO, 2-hexyl-1, 3-benzodioxole; PBDO, 2-proply-1,3-benzodioxole; TEGDMA, triethylene glycol dimethacrylate.

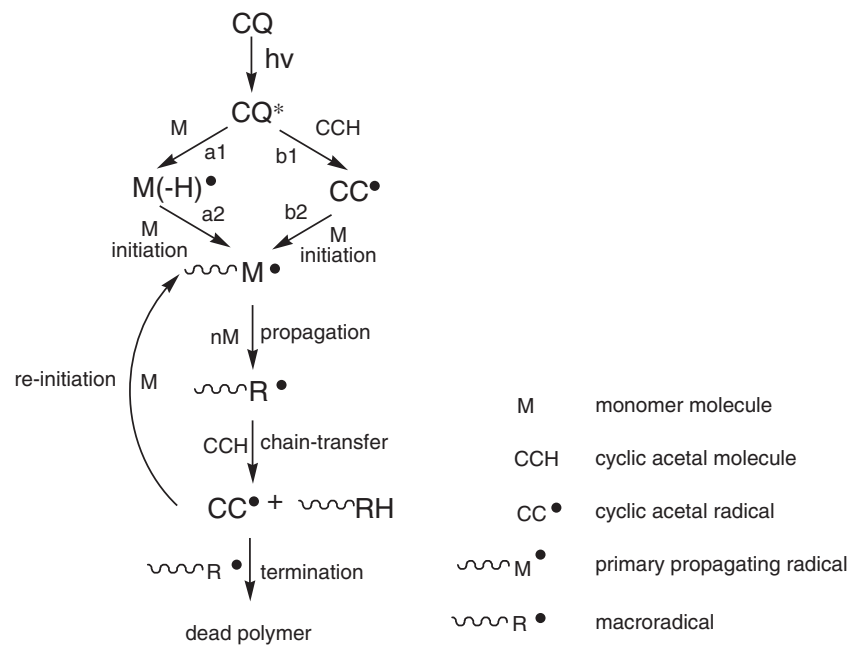

Scheme 1 Proposed mechanism of photoinduced radical generation and polymerization of $C Q$ in the presence of cyclic acetal.

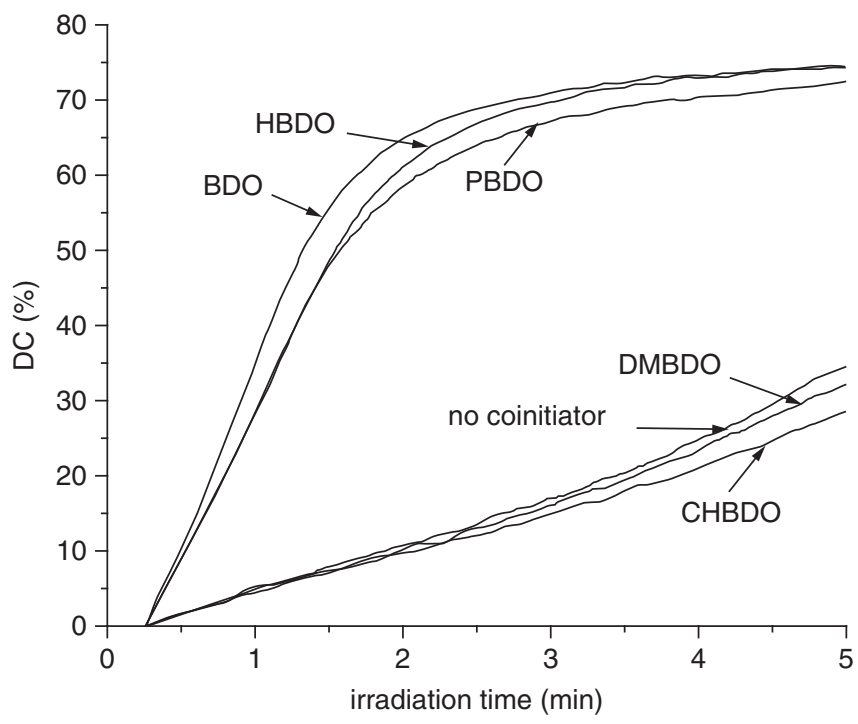

Figure 5 The $D C$ as a function of irradiation time for Bis-GMA/TEGDMA $(70 / 30 \mathrm{wt} \%)$ initiated by $C Q$ in the presence of cyclic acetals. $(C Q)=($ cyclic acetal $)=1 \times 10^{-4} \mathrm{~mol} \mathrm{~g}^{-1}, l=100 \mathrm{~mW} \mathrm{~cm}^{-2}$. 


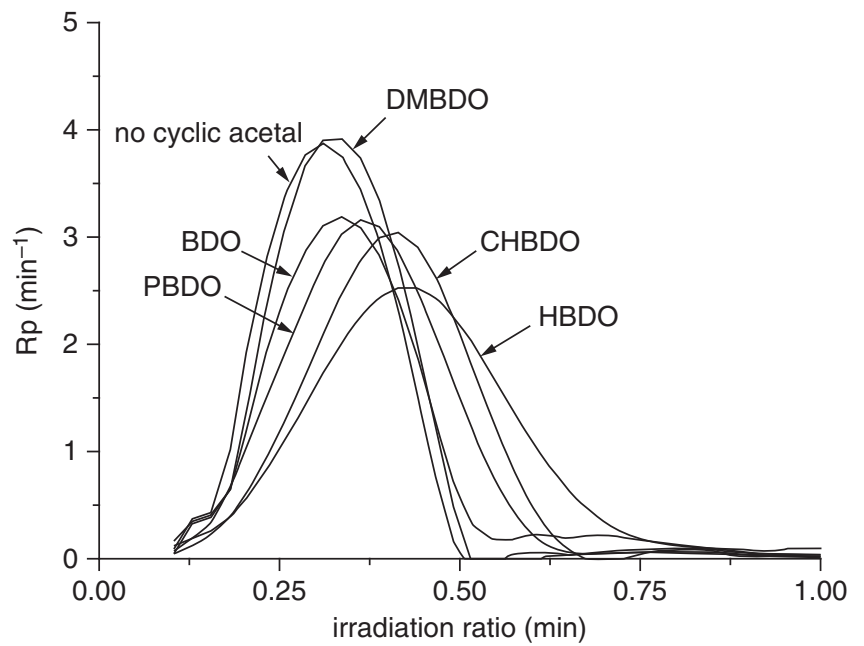

Figure 6 The $R_{p}$ as a function of irradiation time for TEGDMA bulk UV photopolymerizations initiated by $1 \times 10^{-5} \mathrm{~mol} \mathrm{~g}^{-1}$ 2,2-dimethoxy phenylacetophenone in the presence of $1 \times 10^{-4} \mathrm{molg}^{-1}$ cyclic acetals, $l=50 \mathrm{~mW} \mathrm{~cm}^{-2}$.

very high efficiency of the photoinitiator, the molar ratio of 2,2dimethoxy phenylacetophenone to cyclic acetal must be as high as 1:10 for there to be an observable slowing effect from the chain-transfer reaction involving cyclic acetals. Figure 6 shows that DMBDO did not decrease the polymerization rate. The largest effect was observed for HBDO. The cyclic acetals, except for DMBDO, intensified the chaintransfer process, which was more efficient in the presence of HBDO than with other cyclic acetals.

This scenario demonstrated that the influence of cyclic acetals on CQ-induced polymerizations was a combination of two opposing processes: acceleration of initiation through relatively efficient formation of initiating radicals and interference with efficient polymerization through their participation in chain-transfer reaction. The polymerization rate of HBDO was determined mainly by the efficiency of the chain-transfer reaction. The chain-transfer ability is strongest for the HBDO that has a long chain length substituent group on one side of the methylene. The first step of the reaction is the attack of the CQ triplet on the lone electron pairs of cyclic acetals. The next step in photoreduction is proton transfer within the radical-ion pair. Radical formation is also affected by the stability of the radical being formed. Because radical formation is more effective and stable for derivatives containing long chains, HBDO has a strong chain-transfer ability. Although the reactivity of the primary free radical of HBDO was very high, the chain-transfer process was more efficient; as a result, HBDO had the lowest $\mathrm{R}_{\mathrm{p}}^{\max }$. The reactivity of the primary free radical of DMBDO was very low, but the chain-transfer reactions did not occur, resulting in the very high $\mathrm{R}_{\mathrm{p}}^{\max }$ of DMBDO. The reactivity of the primary free radical of BDO was the highest, and the chain-transfer reaction had little effect; hence, the $\mathrm{R}_{\mathrm{p}}^{\max }$ of $\mathrm{BDO}$ was the highest (Figure 4 and Table 2).

\section{CONCLUSION}

The cyclic acetal derivatives were active coinitiators in CQ-induced photopolymerizations. Among the compounds investigated, the photoreduction reactivity of $\mathrm{HBDO}$ was the highest, according to the quantum yield of CQ. The most efficient coinitiator for polymerization was BDO, the reactivity of which significantly exceeded that of HBDO. The activity of cyclic acetals in accelerating CQ-induced polymerization was a result of the efficiency of initiating radical formation (photochemical process, path b1 in Scheme 1), the reactivity of initiating radicals (path b2 in Scheme 1) and the influence of processes resulting from chain transfer to coinitiators (Scheme 1). This step of initiating radical formation was governed by the reactivity of the primary free radicals of cyclic acetals. The subsequent polymerization steps of HBDO depended on the efficiency of the chain-transfer reaction.

\section{ACKNOWLEDGEMENTS}

We thank the National Natural Science Foundation of China (20774010) for its financial support. This study was also supported by Open Funds from the State Key Laboratory of Chemical Resource Engineering, from the Beijing University of Chemical Technology and from the Program for Changjiang Scholars and Innovative Research Team in University.

1 Fouassier, J. P. Photoinitiation, Photopolymerization and Photocuring (Hanser Verlag, Munich, 1995).

2 Davidson, R. S. Exploring the Science, Technology and Applications of UV and EB Curing (SITA Technology Ltd, London, 1999).

3 Fouassier, J. P. \& Rabek, J. F. Radiation Curing in Polymer Science and Technology, vols. I-IV. (Plenum Press, New York, 1992-1993).

4 Gruber, H. F. Photoinitiators for free radical polymerization. Prog. Polym. Sci. 17, 953-1044 (1992).

5 Ledwith, A. \& Purbrich, M. D. Initiation of free-radical polymerization by photoinduced electron-transfer processes. Polymer 14, 521 (1973).

6 Ledwith, A., Bosley, J. A., Purbric, M. D. \& Purbrich, J. Exciplex interactions in photoinitiation of polymerisation by fluorenone-amine systems. Oil. Col. Chem. Assoc. 61, 95-104 (1978).

7 Venhoven, B. A., Gee de, A. J. \& Davidson, C. L. Light initiation of dental resins: dynamics of the polymerization. Biomaterials 17, 2313-2318 (1996).

8 Stansbury, J. W. Curing dental resins and composites by photopolymerization. J Esthet. Dent. 12, 300-308 (2000).

9 Jakubiak, J., Allonas, X., Fouassier, J. P., Sionkowska, A., Andrzejewska, E., Linden, L. A. \& Rabek, J. F. Camphorquinone-amines photinitating systems for the initiation of free radical polymerizastion. Polymer 44, 5219-5226 (2003).

10 Weisburger, E. K., Russfield, A. B., Hamburger, F., Weisburger, J. H., Boger, E., Dongen Van, C. G. \& Chu, K. Testing of twenty-one environmental aromatic amines or derivatives for long term toxicity or carcinogenicity. J. Environ. Pathol. Toxicol. 2, 325-356 (1978).

11 Albrecht, W. N. \& Stephenson, R. L. Health hazards of tertiary amine catalysts. Scand. J. Work Environ. Health 14, 209-219 (1988).

12 Josephy, P. D., Evans, D. H., Parikh, A. \& Guengerich, F. P. Metabolic activation of aromatic amine mutagens by simultaneous expression of human cytochrome P450 1A2, NADPH-cytochrome P450 reductase, and $\mathrm{N}$-acetyltransferase in Escherichia coli. Chem. Res. Toxicol. 11, 70-74 (1998).

13 Arsu, N., Davidson, R. S. \& Holman, R. Factors affecting the photoyellowing which occurs during the photoinitiated polymerization of acrylates. J. Photochem. Photobiol. A 87, 169-175 (1995).

14 Walling, C. Free Radicals in Solution (Wiley, New York, 1957).

15 Elad, D. \& Youssefyeh, R. D. The photochemical conversion of acetals to carboxylic esters. Tetrahedron Lett. 30, 2189 (1963).

16 Ouchi, T., Nakamura, S. \& Hamada, M. Cyclic acetal -photosensitized polymerization. I. photopolymerization of styrene in the presence of 1,3-dioxolanes. J. Polym. Sci. Polym. Chem. 13, 455-466 (1975).

17 Ouchi, T. \& Azuma, T. Acetal-Photosensitized Polymerization. 15 photoirradiations of Maleic anhydride in the presence of 2,4,8,10-tetraoxaspiro [5,5]undecane compounds. Eur. Polym. J. 18, 809-812 (1982).

18 Ouchi, T., Sato, C. \& Yamamoto, T. Cyclic acetal-photosensitized polymerization. XI. photoirradiations onto polycyclic acetals. J. Macromol. Sci. Chem. 14, 265-275 (1980).

19 Mosca, R., Fagnoni, M., Mella, M. \& Albini, A. Synthesis of monoprotected 1, 4-diketones by photoinduced alkylation of enones with 2-substituted-1,3-dioxolanes. Tetrahedron 57, 10319-10328 (2001).

20 Shi, S., Gao, H., Wu, G. \& Nie, J. Cyclic acetal as coinitiator for bimolecular photoinitiating systems. Polymer 48, 2860-2865 (2007).

$21 \mathrm{Shi}, \mathrm{S}$. \& Nie, J. A Natural Component as Coinitiator for Unfilled Dental Resin Composites. J. Biomed. Mater. Res. Appl. Biomater. 23, 44-50 (2007).

22 Iwagami, H., Yatagai, M., Nakazawa, M., Orita, H., Honda, Y., Ohnuki, T. \& Yukawa, T. Synthesis of a chiral $\alpha$-(aminooxy)arylacetic ester. II. A route through a chiral 2-hydroxy2-phenylacetic acid derivative. Bull. Chem. Soc. Jpn. 64, 175-182 (1991).

23 Harvison, P. J., Forte, A. J. \& Nelson, S. D. Comparative toxicities and analgesic activities of three monomethylated analogs of acetaminophen. J. Med. Chem. 29, 1737-1743 (1986). 
24 Cole, E. R., Crank, G. \& Minh, H. T. H. An improved method for the synthesis of 2,2disubstituted and 2-monosubstituted 1,3-benzodioxoles. Aus. J. Chem. 33, 675-680 (1980).

25 Jakubiak, J., Nie, J., Linden, L. A. \& Rabek, J. F. Crosslinking photocopolymerization of acrylic acid (and $\mathrm{N}$-vinylpyrrolidone) with triethyleneglycol dimethacrylate initiated by camphorquinone/ethyl-4-dimethylaminobenzoate. J. Polym. Sci. Polym. Chem. 38, 876-886 (2000).

$26 \mathrm{Wu}, \mathrm{G} ., \mathrm{Shi}, \mathrm{S} .$, Xiao, P. \& Nie, J. Synthesis and characterization of aliphatic amine co-initiator with different chain length for photopolymerization of dimethacrylate. J. Photochem. Photobiol. A 188, 260-266 (2007).
27 Scherzer, T., Müller, S., Mehnert, R., Volland, A. \& Lucht, H. In-line monitoring of the conversion in photopolymerized acrylate coatings on polymer foils using NIR spectroscopy. Polymer 46, 7072-7081 (2005).

28 Stansbury, J. W. \& Dickens, S. H. Determinationof double bond conversion in dental resins by near infrared spectroscopy. Dent. Mater. 17, 71-79 (2001).

29 Decker, C. \& Moussa, K. Real-time kinetic study of laser-induced polymerization. Macromolecules 22, 4455-4465 (1989).

30 Andrzejewska, E., Hug, G. L., Andrzejewski, M. \& Marciniak, B. Trithianes as coinitiators in benzophenone-induced photopolymerizations. Macromolecules 32 , 2173-2179 (1999). 